\title{
Intraoperative use of recombinant activated factor VII during complex aortic surgery
}

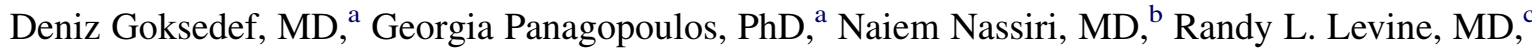 \\ Panagiotis G. Hountis, MD, ${ }^{\mathrm{a}}$ and Konstadinos A. Plestis, $\mathrm{MD}^{\mathrm{a}}$
}

\begin{abstract}
Objective: Postoperative bleeding is a major cause of morbidity and mortality after complex aortic surgery. Intraoperative coagulopathy is a well-known culprit in this process. Recombinant activated factor VII is increasingly used for the postoperative management of such bleeding. We report our experience with the intraoperative use of this agent.
\end{abstract}

\begin{abstract}
Methods: We performed a propensity-matched analysis on 376 retrospectively identified patients who underwent aortic root, arch, or ascending aortic replacement surgeries from 1999 to 2010 . We matched a total of 58 patients: recombinant activated factor VII-treated group $(\mathrm{n}=29)$ and nonrecombinant activated factor VII-treated group $(\mathrm{n}=29)$. We compared the matched patients on re-exploration, mortality, bleeding-related events, use of blood and blood products, length of intensive care unit stay, duration of hospitalization, and thrombotic complications.
\end{abstract}

Results: Propensity-matched patients had similar preoperative and intraoperative characteristics. The mean dose of recombinant activated factor VII group was $23 \pm 12 \mu \mathrm{g} / \mathrm{kg}$. We found significantly lower rates of surgical re-exploration $(P=.004)$, fewer prolonged intubations $(P=.004)$, less total chest tube output $(P=.01)$, and fewer units of packed red blood cells $(P=.01)$ and fresh-frozen plasma $(P=.04)$ transfused postoperatively in the recombinant activated factor VII group. There was no significant difference in mortality $(P=1)$, duration of intensive care unit stay $(P=.44)$ or hospital stay $(P=.32)$, or thrombotic complications between the groups $(P=.5)$.

Conclusions: We recommend the intraoperative administration of low-dose recombinant activated factor VII but limited to the management of persistent, nonsurgical, mediastinal bleeding in aortic surgery. Further prospective randomized studies and larger cohorts are needed to verify these findings. (J Thorac Cardiovasc Surg 2012;143:1198-204)

Repair of aortic root, ascending aorta, and aortic arch aneurysms is associated with significant postoperative bleeding that often requires transfusion of large volumes of blood and blood products. ${ }^{1}$ This is a well-known risk factor for postoperative morbidity and has been reported to cause an 8.1 -fold increase in mortality rates. ${ }^{2}$ In patients undergoing re-exploration for postoperative bleeding after cardiac surgery, it has been demonstrated that only $50 \%$ have a grossly identifiable surgical source of bleeding. ${ }^{3}$ This identifies microvascular bleeding caused by coagulopathy as a major risk factor for postoperative bleeding. Strategies to prevent coagulopathic bleeding are essential for the successful management of patients undergoing complex aortic operations.

Recombinant activated factor VII (rFVIIa; NovoSeven, NovoNordisk, Copenhagen, Denmark) was initially

From the Aortic Wellness Center, ${ }^{\mathrm{a}}$ Department of Vascular Surgery, ${ }^{\mathrm{b}}$ and Department of Blood Bank, ${ }^{\mathrm{c}}$ Lenox Hill Hospital, New York, NY.

Disclosures: Authors have nothing to disclose with regard to commercial support.

Received for publication Sept 13, 2011; revisions received Nov 23, 2011; accepted for publication Jan 4, 2012; available ahead of print Jan 30, 2012

Address for reprints: Deniz Goksedef, MD, Aortic Wellness Center, Lenox Hill Hospital, 130 East 77th street, 4th Floor, New York, NY, 10075 (E-mail: denizgoksedef@yahoo.com).

0022-5223/\$0.00

Published by Elsevier Inc. on behalf of The American Association for Thoracic Surgery

doi:10.1016/j.jtcvs.2012.01.004 developed for management of bleeding in hemophiliacs. ${ }^{4,5}$ Over the last decade, rFVIIa has been increasingly used in the postoperative management of intractable bleeding after cardiac and aortic surgery. ${ }^{6}$ Of note, the precise dose required to control bleeding without causing thrombotic complications is controversial. ${ }^{7}$ Dose recommendations in the current literature have ranged from 30 to $200 \mu \mathrm{g} / \mathrm{kg}$, which can be administered in multiple doses.

Currently, there are a paucity of data regarding the intraoperative use of rFVIIa as a measure to minimize postoperative bleeding and associated complications. ${ }^{8}$ We report our clinical experience with off-label intraoperative use of low-dose rFVIIa for inadequate hemostasis in patients undergoing complex aortic repair procedures.

\section{MATERIAL AND METHODS Study Population}

Patients were retrospectively identified from our aortic aneurysm research registry. From 1999 to 2010, 488 patients underwent repair of the aortic root, ascending aorta, and arch (Table 1). Excluded from the study were the patients undergoing concomitant coronary artery bypass grafting, mitral or tricuspid valve surgery, and congenital surgery. We further excluded patients who had abnormalities in the preoperative coagulation panel (prothrombin time, partial thromboplastin time, bleeding time, and platelet count [if $<150 \mathrm{k} / \mathrm{mL}]$ ). The above exclusion criteria narrowed the pool to 376 patients. In February 2009, we started administering 


\author{
Abbreviations and Acronyms \\ DHCA $=$ deep hypothermic circulatory arrest \\ FFP $=$ fresh-frozen plasma \\ ICU = intensive care unit \\ $\mathrm{POD}=$ postoperative day \\ PRBC $=$ packed red blood cell \\ rFVIIa $=$ recombinant activated factor VII
}

intraoperative off-label rFVIIa to patients who met our clinical criteria as outlined below. We identified 37 such patients. The remaining patients served as a control pool for the propensity-matched analysis.

\section{Study End Points}

The primary end points of our study were major bleeding requiring surgical re-exploration and postoperative in-hospital death. Secondary end points were the use of blood and blood products, delayed chest closure, postoperative tamponade, chest tube output, duration of intensive care unit (ICU) stay, prolonged intubation ( $>48$ hours), duration of hospitalization, and any complication that might be related to thrombosis.

\section{Data Collection}

Preoperative and intraoperative data are listed in Table 2. The institutional review board approved the use of these data for the purposes of this study. All patients undergoing aortic surgery after 2009 were informed in advance that they might receive factor VII.

\section{Surgical Technique}

After endotracheal intubation and administration of appropriate anesthetic agents, radial arterial, central venous, and Swan-Ganz catheters were introduced per routine. Median sternotomy was performed followed by arterial and venous cannulations as outlined below. Standard cardiopulmonary bypass technique was carried out using membrane oxygenators. Of note, 152 patients $(40 \%)$ received right axillary cannulation for arterial access. Venous access was obtained via cannulation of the right atrium or the femoral vein. Depending on the complexity of the procedure, moderate to deep systemic hypothermia was used. Mean arterial blood pressure was kept between 50 and $70 \mathrm{~mm} \mathrm{Hg}$ during cardiopulmonary bypass. Myocardial protection was achieved by antegrade and retrograde cold blood cardioplegia. Heparin was administered to achieve an activated clotting time more than 480 seconds. This was neutralized with appropriate use of protamine administered within 10 minutes after the end of cardiopulmonary bypass. All patients received aminocaproic acid (AMICAR; Lederle Parenterals, Carolina, Puerto Rico) perioperatively. Generally accepted criteria were used for re-exploring patients with postoperative bleeding. ${ }^{9}$

\section{Management of Intraoperative Bleeding}

Figure 1 summarizes the algorithm we used to treat intraoperative bleeding. Beginning in February 2009, rFVIIa was added to this regimen as described below. If bleeding persisted after routine attempts at surgical hemostasis, coagulation parameters were measured to rule out any existing correctable measures. If none existed or corrected, rFVIIa was administered at 1 to $2 \mathrm{mg} / \mathrm{dose}(10-30 \mu \mathrm{g} / \mathrm{kg}$ ), which was repeated once if bleeding persisted. If the surgeon was not satisfied with the degree of hemostasis despite these measures, the chest was left open and packed with continuous negative pressure suction dressing for delayed closure. The patient was subsequently transferred to the ICU for observation and brought back to the operating room within 24 to 72 hours for definitive closure.

\section{Statistical Analysis}

Demographic, perioperative, and intraoperative continuous variables were compared using the unpaired or paired $t$ test for the prematch and propensity-matched groups, respectively. Accordingly, dichotomous variables were compared using the Fisher exact or McNemar test.

Because of the absence of preoperative randomization, a propensitymatched analysis was performed. ${ }^{10}$ Propensity scores were generated through a logistic regression procedure using the following risk factors observed to be significant in the univariate prematch group comparisons and deemed likely to cause postoperative bleeding: gender, total body surface area, emergency status of the operation, total pump time, redo sternotomy, and use of deep hypothermic circulatory arrest (DHCA). Once generated, propensity scores were addressed as proposed by Austin. ${ }^{11}$ Matching without the replacement method was used to pick up a match from the control group. Finally, patients were matched by an identical 5 -digit propensity score. If this could not be done, we then proceeded to a 4-, 3-, 2-, or 1-digit match. Five-digit matches were 11, and 4-3-2-1 matches were $6,6,4$, and 2 , respectively. We were unable to match 8 patients who had rFVIIa; therefore, we excluded those from further analysis.

Values are expressed as mean \pm standard deviation, median (minimummaximum), or percentage. All analyses were performed with SPSS 13.0 software (SPSS Inc, Chicago, Ill).

\section{RESULTS \\ Total Prematch Group}

The mean age was $63 \pm 13$ years (19-88), and $64 \%$ were male. The mean intraoperative dose of rFVIIa in 37 patients was $23 \pm 14 \mu \mathrm{g} / \mathrm{kg}(10-60)$. Nineteen patients received $1 \mathrm{mg}$ of rFVIIa (51\%), 13 patients ( $35 \%$ ) received $2 \mathrm{mg}$ of rFVIIa, 4 patients $(10 \%)$ received $3 \mathrm{mg}$ of rFVIIa, and 1 patient $(2 \%)$ received $4 \mathrm{mg}$ of $\mathrm{rFVII}$ a before leaving the operating room. Of note, none of the patients received additional doses of rFVIIa after leaving the operating room. The patient who required $4 \mathrm{mg}$ of $\mathrm{rFVIIa}$ had had an acute type A dissection requiring replacement of the aortic root, arch, and ascending aorta. Furthermore, the patient was anticoagulated with argatroban because of a standing diagnosis of heparin-induced thrombocytopenia with a preoperative platelet count of $155 \times 10^{3} / \mathrm{mL}$.

\section{Prematch Comparison}

All performed operations are listed in Table 1. The ascending aorta was involved in 195 patients $(51 \%)$, the aortic root was involved in 94 patients $(25 \%)$, and the aortic arch was involved in 105 patients (28\%). Prematch baseline variables are shown in Table 2 . In the prematch analysis, there were significantly more male patients in the control group $(P=.02)$. The rFVIIa group had longer total pump time $(P=.008)$ and aortic crossclamp time $(P=.006)$. Redo sternotomy was performed in 10 patients $(27 \%)$ in the rFVIIa group and in 39 patients $(11 \%)$ in the control group $(P=.01)$. Other preoperative variables were not statistically different.

\section{Postmatch Comparison}

The propensity-matched analysis yielded 58 patients available for analysis. All variables before administration of rFVIIa were similar between the 2 groups (Table 2). 
TABLE 1. Performed operations ( $\%)$

\begin{tabular}{|c|c|c|c|c|c|c|}
\hline & \multicolumn{3}{|c|}{ Before match } & \multicolumn{3}{|c|}{ After match } \\
\hline & Overall $(\mathbf{n}=376)$ & rFVIIa $(n=37)$ & Control $(\mathbf{n}=339)$ & Overall $(\mathbf{n}=58)$ & rFVIIa $(n=29)$ & Control $(n=29)$ \\
\hline Ascending $\pm \operatorname{arch} \pm$ AV repair & $27(7)$ & 0 & $27(7)$ & 0 & 0 & 0 \\
\hline $\begin{array}{l}\text { Ascending } \pm \text { arch } \pm \mathrm{AV} \\
\text { replacement }\end{array}$ & $82(21)$ & $1(2)$ & $81(23)$ & $1(2)$ & $1(3)$ & 0 \\
\hline Ascending aorta replacement & $101(26)$ & $4(10)$ & $97(28)$ & $7(12)$ & $3(10)$ & $4(14)$ \\
\hline Root repair + ascending & $26(6)$ & $1(2)$ & $25(7)$ & $3(5)$ & $1(3)$ & $2(7)$ \\
\hline Root + ascending & $31(8)$ & $6(16)$ & $25(7)$ & $11(19)$ & $5(17)$ & $6(20)$ \\
\hline Root repair + ascending + arch & $4(1)$ & $2(5)$ & $2(0.5)$ & $4(7)$ & $2(7)$ & $2(7)$ \\
\hline Root + ascending + arch & $33(8)$ & $9(24)$ & $24(7)$ & $13(22)$ & $7(24)$ & $6(20)$ \\
\hline Ascending + arch & $58(15)$ & $14(37)$ & $44(12)$ & $17(29)$ & $10(34)$ & $7(24)$ \\
\hline Isolated arch & $14(3)$ & 0 & $14(4)$ & $2(3)$ & 0 & $2(7)$ \\
\hline
\end{tabular}

$A V$, Aortic valve; $r F V I I a$, recombinant-activated factor.

The mean intraoperative dose of rFVIIa was $23 \pm 12 \mu \mathrm{g} /$ $\mathrm{kg}(10-55)$. Fifteen patients received $1 \mathrm{mg}$ of rFVIIa (51\%), 10 patients $(34 \%)$ received $2 \mathrm{mg}$ of rFVIIa, and 4 patients $(13 \%)$ received $3 \mathrm{mg}$ of $\mathrm{rFVII}$ a before leaving the operating room. The rFVIIa group received significantly fewer units of packed red blood cells (PRBCs) $(7 \pm 2$ vs $9 \pm 4$, $P=.01)$ and fresh-frozen plasma (FFP) ( $4 \pm 1$ vs $6 \pm 2$, $P=.04$ ) in the postoperative period (Table 3). There was a tendency for the rFVIIa group to receive fewer units of single-donor platelets and cryoprecipitate, but these values did not reach statistical significance $(P=.097$ and $P=.091$, respectively).

Five patients $(17 \%)$ underwent surgical re-exploration for bleeding in the rFVIIa group compared with 14 patients $(48 \%)$ in the control group $(P=.004)$. None of the reexplored patients had a surgical source of bleeding. One patient $(3 \%)$ in the rFVIIa group had postoperative cardiac tamponade (caused by excessive packing in a patient who underwent open chest surgery) compared with 4 patients $(13 \%)$ in the control group $(P=.25)$ (Table 3$)$. Patients receiving rFVIIa had lower total chest tube output when compared with the control group $(810 \pm 376 \mathrm{~mL}$ vs $1020 \pm 515$ $\mathrm{mL}, P=.01$, respectively). All patients had adequate hemostasis before chest closure; 7 patients had delayed chest closure, and mean chest closure time was $1.4 \pm 0.7$ days (1-3) after the initial operation. Two patients $(6 \%)$ in the rFVIIa group and 5 patients $(17 \%)$ in the control group had delayed chest closure $(P=.25)$.

The median ICU stay was 2 days in the rFVIIa group (range, 1-7) compared with 3 days in the control group (range, 1-15). The rate of prolonged intubation was significantly lower in the rFVIIa group compared with the control

TABLE 2. Preoperative and operative characteristics of overall population and comparison between recombinant activated factor VII and control group before and after propensity match

\begin{tabular}{|c|c|c|c|c|c|c|c|c|}
\hline \multirow[b]{2}{*}{ Variable } & \multicolumn{4}{|c|}{ Before match } & \multicolumn{4}{|c|}{ After match } \\
\hline & $\begin{array}{c}\text { Overall } \\
(n=376)\end{array}$ & $\begin{array}{l}\text { rFVIIa } \\
(\mathbf{n}=\mathbf{3 7})\end{array}$ & $\begin{array}{c}\text { Control } \\
(\mathbf{n}=\mathbf{3 3 9})\end{array}$ & $P$ value & $\begin{array}{c}\text { Overall } \\
(n=58)\end{array}$ & $\begin{array}{c}\text { rFVIIa } \\
(n=29)\end{array}$ & $\begin{array}{l}\text { Control } \\
(n=29)\end{array}$ & $P$ value \\
\hline Age (y) & $63 \pm 13$ & $59 \pm 12$ & $63 \pm 13$ & .12 & $60.3 \pm 12$ & $60.3 \pm 11$ & $60.3 \pm 13$ & .62 \\
\hline Gender (male, \%) & $244(64)$ & $18(48)$ & $226(66)$ & .02 & $29(50)$ & $14(48)$ & $15(51)$ & 1 \\
\hline Body surface area $\left(\mathrm{m}^{2}\right)$ & $1.83 \pm 0.2$ & $1.81 \pm 0.1$ & $1.84 \pm 0.2$ & .3 & $1.82 \pm 0.1$ & $1.81 \pm 0.1$ & $1.82 \pm 0.1$ & .98 \\
\hline Hypertension (\%) & $304(81)$ & $30(81)$ & $267(78)$ & .46 & $46(80)$ & $24(82)$ & $22(75)$ & .5 \\
\hline COPD $(\%)$ & $87(23)$ & $10(27)$ & $77(22)$ & .34 & $12(20)$ & $6(20)$ & $6(20)$ & 1 \\
\hline euroSCORE $(\%)$ & $6.3 \pm 3.2$ & $6.5 \pm 3.1$ & $6.3 \pm 3.2$ & .62 & $6.5 \pm 3.1$ & $6.7 \pm 3.5$ & $6.3 \pm 2.7$ & .59 \\
\hline Renal dysfunction (\%) & $27(7)$ & $3(8)$ & $26(7)$ & .56 & $5(8)$ & $2(6)$ & $3(10)$ & 1 \\
\hline Preoperative EF (\%) & $66 \pm 13$ & $64 \pm 16$ & $66 \pm 12$ & .74 & $65 \pm 13$ & $65 \pm 11$ & $65 \pm 14$ & .94 \\
\hline Emergency surgery $(\%)$ & $72(19)$ & $6(16)$ & $66(19)$ & .41 & $11(18)$ & $5(17)$ & $6(21)$ & 1 \\
\hline Acute dissection (\%) & $57(15)$ & $5(13)$ & $52(15)$ & .49 & $7(12)$ & $3(10)$ & $4(14)$ & 1 \\
\hline Chronic dissection $(\%)$ & $13(3)$ & $1(2)$ & $12(3)$ & .62 & $1(1)$ & 0 & $1(3)$ & 1 \\
\hline Redo sternotomy (\%) & $49(13)$ & $10(27)$ & $39(11)$ & .01 & $11(18)$ & $6(21)$ & $5(17)$ & 1 \\
\hline TPT (min) & $196 \pm 70$ & $227 \pm 65$ & $193 \pm 70$ & .008 & $212 \pm 61$ & $220 \pm 64$ & $203 \pm 59$ & .17 \\
\hline ACC time (min) & $133 \pm 65$ & $165 \pm 76$ & $132 \pm 64$ & .006 & $135 \pm 62$ & $142 \pm 73$ & $128 \pm 49$ & .23 \\
\hline DHCA $(\%)$ & $267(71)$ & $25(67)$ & $242(71)$ & .7 & $45(77)$ & $22(75)$ & $23(79)$ & 1 \\
\hline
\end{tabular}

$A C C$, Aortic crossclamp time; $C O P D$, chronic obstructive pulmonary disease; $D H C A$, deep hypothermic circulatory arrest; $E F$, ejection fraction; $r F V I I a$, recombinant activated factor VII; TPT, total pump time; euroSCORE, European System for Cardiac Operative Risk Evaluation. 


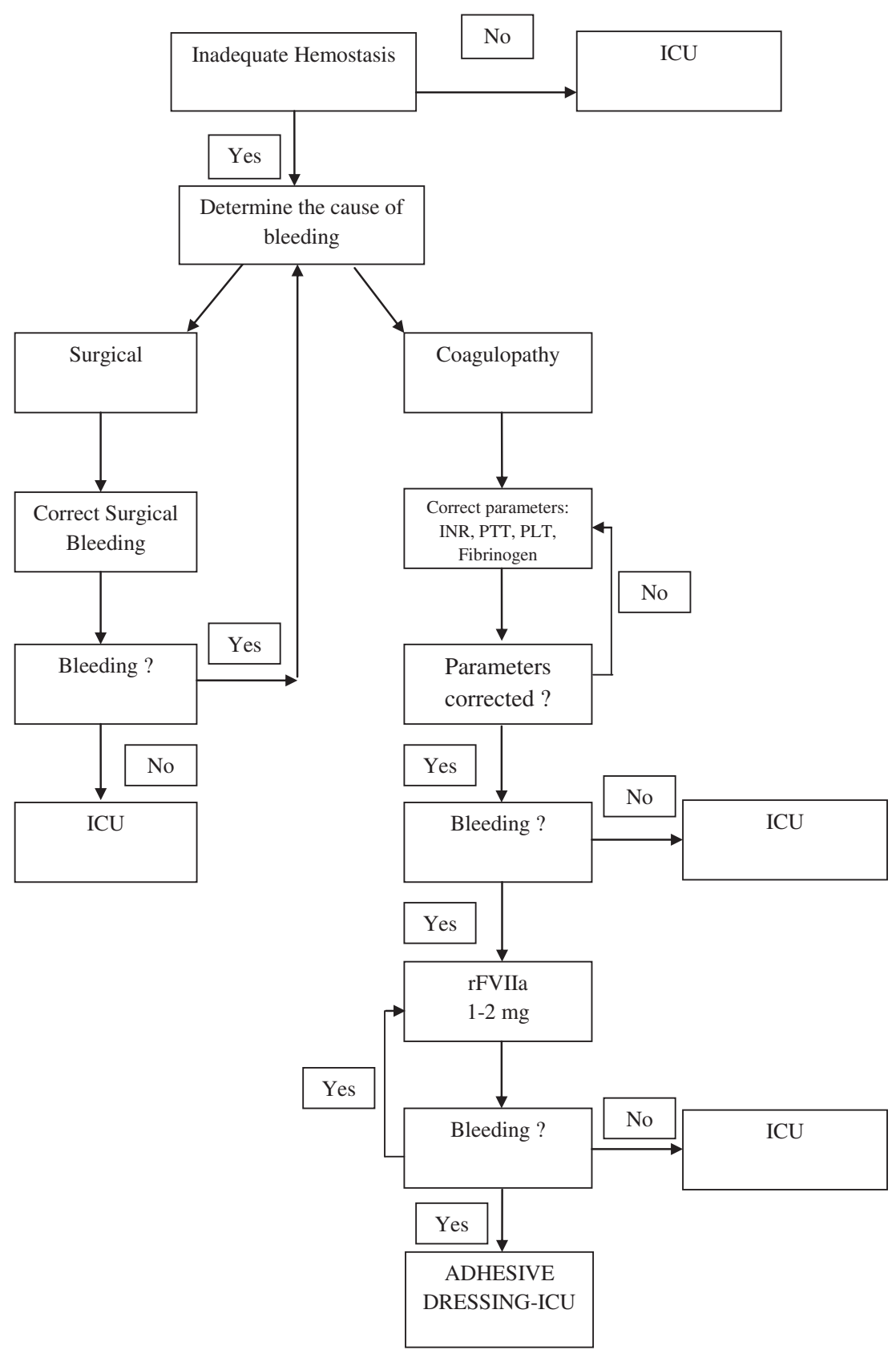

FIGURE 1. Hemostasis management in aortic surgery. ICU, Intensive care unit; INR, international normalized ratio; PTT, prothrombin time; PLT, platelet; rFVIIa, recombinant activated factor VII.

group $(27 \%$ vs $58 \%, P=.004)$. There was no difference in the length of ICU stay $(P=.44)$ or duration of hospital stay $(P=.32)$ between the groups (Table 3$)$.

There were 6 thrombotic complications in 6 patients $(10 \%)$ (Table 4). In the rFVIIa group, 1 patient had a stroke and 1 patient had a transient ischemic attack (7\%). In the control group, 2 patients had a stroke, 1 patient had a transient ischemic attack, and 1 patient had a myocardial infarction. There was no statistically significant difference in the number of thrombotic events between the 2 groups $(P=.5)$.
Overall 30-day mortality was 4 of 58 patients $(6 \%)$, with 2 mortalities in each group. In the rFVIIa group, the first mortality occurred in a patient who had developed heparin-induced thrombocytopenia in addition to acute postoperative renal failure and concomitant sepsis after a reoperation of aortic root, arch, and ascending aortic replacement. This patient died on postoperative day (POD) 17. The second mortality also occurred in a patient who underwent a redo aortic root replacement for an infected mechanical valve. The coronaries were reimplanted using the Cabrol 
TABLE 3. Postoperative blood and blood product use and bleedingrelated complications in matched patients

\begin{tabular}{lccc}
\hline & $\begin{array}{c}\text { rFVIIa } \\
(\mathbf{n = 2 9 )}\end{array}$ & $\begin{array}{c}\text { Control } \\
(\mathbf{n = 2 9 )}\end{array}$ & $\begin{array}{c}\boldsymbol{P} \\
\text { value }\end{array}$ \\
\hline Blood and blood product use & & & \\
$\quad$ PRBC (units) & $7 \pm 2$ & $9 \pm 4$ & .01 \\
FFP (units) & $4 \pm 1$ & $6 \pm 2$ & .04 \\
Platelets (single donor) & $3 \pm 2$ & $4 \pm 2$ & .097 \\
Cryoprecipitate (units) & $12 \pm 2$ & $14 \pm 3$ & .091 \\
Clinical bleeding-related complications & & & \\
Delayed chest closure (\%) & $2(6)$ & $5(17)$ & .25 \\
Postoperative tamponade (\%) & $1(3)$ & $4(13)$ & .25 \\
Re-exploration (\%) & $5(17)$ & $14(48)$ & .004 \\
Total average chest tube output (mL) & $810 \pm 376$ & $1020 \pm 515$ & .01 \\
Hospital outcomes & & & \\
Median ICU stay (d) & $2(1-7)$ & $3(1-15)$ & .44 \\
Prolonged intubation (\%) & $8(27)$ & $17(58)$ & .004 \\
ARDS & $2(6)$ & $5(17)$ & .25 \\
Pulmonary infection & $2(6)$ & $3(10)$ & 1 \\
Duration of hospitalization (d) & $9 \pm 5$ & $10 \pm 7$ & .32 \\
Mortality (\%) & $2(6)$ & $2(6)$ & 1 \\
\hline
\end{tabular}

$F F P$, Fresh-frozen plasma; $I C U$, intensive care unit; $P R B C$, packed red blood cell; $r F V I I a$, recombinant activated factor VII; $A R D S$, acute respiratory distress syndrome.

technique. Sudden cardiac arrest developed in this patient on POD 5 from an episode of aspiration and subsequently died after failed attempts at resuscitation and a trial of extracorporeal membrane oxygenation. At the time of postmortem autopsy, the coronary interposition grafts were patent.

In the control group, the first death occurred from multiorgan failure on POD 14 in a patient who had undergone aortic root and ascending aortic replacement. This patient was re-explored on POD 2 for persistent mediastinal bleeding. The second death in this group occurred on POD 6 in a similar patient who had persistent postoperative bleeding requiring re-exploration. The patient eventually expired from overwhelming sepsis with subsequent cardiac and renal failure. The patient underwent repair of acute type A dissection with preoperative tamponade.

\section{DISCUSSION}

The development of an approach for the management of inadequate hemostasis due to coagulopathy after aortic

TABLE 4. Total thrombosis-related events (n)

\begin{tabular}{lccc}
\hline & rFVIIa $\mathbf{n}=\mathbf{2 9}$ & Control $\mathbf{n}=\mathbf{2 9}$ & Total $\mathbf{n}=\mathbf{5 8}$ \\
\hline Stroke & 1 & 2 & 3 \\
TIA & 1 & 1 & 2 \\
MI & 0 & 1 & 1 \\
Venous thrombosis & 0 & 0 & 0 \\
PE & 0 & 0 & 0 \\
Arterial thrombosis & 0 & 0 & 0 \\
Total & 2 & 4 & 6 \\
\hline
\end{tabular}

TIA, Transient ischemic attack; $M I$, myocardial infarction; $P E$, pulmonary embolism; $r F V I I a$, recombinant activated factor VII. surgery is essential to have better outcomes. ${ }^{12}$ Such management must start at the beginning of the operation to preserve the hemostatic system. Aprotinin has been widely used to reduce blood loss and blood transfusion requirements after thoracic aortic operations ${ }^{13}$; however, there is controversy on the use of aprotinin because of its reported side effects on renal function ${ }^{14}$ and mortality. In the postaprotinin era, there is no consensus for any agent to reduce bleeding after aortic operations.

Despite its potential for increasing rates of thrombotic complications, rFVIIa has been shown to be effective in the management of uncontrolled bleeding after major operations. ${ }^{6,15-17}$ In several small randomized trials, postoperative administration of rFVIIa has been associated with fewer blood transfusions and lower mortality rates particularly if limited to therapeutic doses of $90 \mu \mathrm{g} / \mathrm{kg} .{ }^{18}$ There currently exist no standardized criteria for the off-label use of rFVIIa intra- or postoperatively in cardiovascular surgery. To our knowledge, this study represents the largest report of intraoperative off-label use of rFVIIa in patients undergoing cardiothoracic surgery. A randomized trial also showed the efficacy of intraoperative use in only 10 patients with an rFVIIa dose of $90 \mu \mathrm{g} / \mathrm{kg} .{ }^{19} \mathrm{In}$ addition, we have used lower therapeutic doses compared with those that have been reported. ${ }^{16,20}$ However, several other reviews of the literature have demonstrated a potential association with the complications. In addition, the recent randomized controlled trial by Gill and colleagues $^{21}$ demonstrated a nonsignificant doubling of serious adverse events and mortality in patients randomly assigned to receive rFVIIa for the management of excessive postoperative bleeding after cardiac surgery. Several recombinant and purified coagulation products are being studied, and those such as rFVIIa may provide clinicians specific agents to treat targeted deficiencies; however, safety is still the most important debate of these therapies. ${ }^{12}$

In this study, patients receiving intraoperative rFVIIa had significantly lower rates of re-exploration for bleeding when compared with a propensity-matched control group of patients $(17 \%$ vs $48 \%, P=.004)$. In addition, patients receiving rFVIIa had significantly lower amounts of chest tube output, PRBC, and FFP transfusions. It is possible that the early intraoperative administration of rFVIIa allows it to exert its effects before the onset of such events and potentially reduces the dose required for successful management of coagulopathic bleeding. Some experimental ${ }^{22}$ and clinical ${ }^{7}$ studies have shown that hypothermia and acidosis may have a negative impact on the efficacy of rFVIIa. Several factors, including hemorrhage and transfusion of blood and blood products, are major contributors to the development of postoperative hypothermia and acidosis. Further experimental studies and larger clinical cohorts are needed to verify the potential benefit of earlier 
administration of low-dose rFVIIa. However, a trend for increased mortality was observed in both low- and mediumdosing schedules of rFVIIa when this agent was used as a first-line therapy in a recent randomized controlled trial. ${ }^{21}$

The incidence of prolonged intubation in the rFVIIa group was lower than that in the control group. It is a well-known fact that excessive bleeding after open surgery is an important factor that can prevent early extubation. ${ }^{23}$ The lower incidence of prolonged intubation in the rFVIIa group may also be due to fewer PRBC and FFP transfusions and the decreased incidence of surgical reexploration due to mediastinal bleeding in the rFVIIa group. However, intraoperative rFVIIa treatment did not affect the median ICU stay, hospital stay, and in-hospital mortality.

The safety of rFVIIa has been controversial owing to its reported risk of increased thrombotic complications. ${ }^{24} \mathrm{Sev}$ eral reports suggest that a range of 45 to $90 \mu \mathrm{g} / \mathrm{kg}$ might be safe and effective when administered postoperatively. ${ }^{25}$ With our low-dose regimen, we had only 2 patients $(7 \%)$ with potential thrombosis-related events. A multinational registry of rFVIIa use in patients undergoing cardiac surgery suggests a $4 \%$ thromboembolic event rate and a $7 \%$ possible or probable adverse event rate at a dose of $92 \mu \mathrm{g} /$ $\mathrm{kg}$ related to the use of rFVIIa. ${ }^{7}$ This study included $37 \%$ of aortic cases in which $9 \%$ were related to the aortic arch. In our study, $62 \%$ of operations involved the aortic arch and $77 \%$ of patients underwent operations with DHCA, facts that demonstrate the increased complexity of the operations. Indeed, we found no significant difference between the rates of thrombotic complications between groups. In this study, mortality was not related to thrombotic complications. The safety of our lower dose may be attributed to the earlier administration of rFVIIa and second tier than previously reported. ${ }^{21}$

\section{Study Limitations}

Our study is limited by several factors. This is a retrospective study and is therefore associated with the known biases of such studies. Furthermore, there was a significant difference in baseline prematch variables, thereby mandating the performance of a propensity-matched analysis as outlined previously. This method of propensity match itself was limited by the small number of patients included in the statistical analysis who received rFVIIa. The findings of this study cannot be applied to cases involving coronary revascularization because of the possible detrimental thrombosis-related complications of the small size of coronary arteries. Last, although there was no safety signal detected, this study has inadequate power to detect a difference in serious adverse events or complications. We strongly advocate that future prospective randomized trials be conducted to verify our findings.

\section{CONCLUSIONS}

This study shows that the intraoperative low dose of rFVIIa is effective in reducing re-exploration for bleeding, decreasing the need for PRBC and FFP transfusions, and reducing the chest tube output. On the basis of the preliminary results, we recommend that clinicians consider the intraoperative use of low doses of rFVIIa in aortic surgery for managing inadequate hemostasis that is unresponsive to routine hemostatic therapy (eg, platelets, FFP, cryoprecipitate). Further prospective randomized studies and larger cohorts are needed to verify these findings.

The authors thank Maminder Bhatti for the contribution in data collection.

\section{References}

1. Gertler JP, Cambria RP, Brewster DC, Davison JK, Purcell P, Zannetti S, et al. Coagulation changes during thoracoabdominal aneurysm repair. $J$ Vasc Surg. 1996;24:936-43

2. Karkouti K, Wijeysundera DN, Yau TM, Beattie WS, Abdelnaem E, McCluskey SA, et al. The independent association of massive blood loss with mortality in cardiac surgery. Transfusion. 2004;44:1453-62.

3. Moulton MJ, Creswell LL, Mackey ME, Cox JL, Rosenbloom M. Reexploration for bleeding is a risk factor for adverse outcomes after cardiac operations. J Thorac Cardiovasc Surg. 1996;111:1037-46.

4. Lusher JM, Roberts HR, Davignon G, Joist JH, Smith H, Shapiro A, et al. A randomized, double-blind comparison of two dosage levels of recombinant factor VIIa in the treatment of joint, muscle and mucocutaneous haemorrhages in persons with haemophilia A and B, with and without inhibitors. rFVIIa Study Group. Haemophilia. 1998;4:790-8

5. Shapiro AD, Gilchrist GS, Hoots WK, Cooper HA, Gastineau DA. Prospective, randomised trial of two doses of rFVIIa (NovoSeven) in haemophilia patients with inhibitors undergoing surgery. Thromb Haemost. 1998;80:773-8.

6. Warren O, Mandal K, Hadjianastassiou V, Knowlton L, Panesar S, John K, et al. Recombinant activated factor vii in cardiac surgery: a systematic review. Ann Thorac Surg. 2007;83:707-14.

7. Dunkley S, Phillips L, McCall P, Brereton J, Lindeman R, Jankelowitz G, et al. Recombinant activated factor vii in cardiac surgery: experience from the Australian and New Zealand Haemostasis Registry. Ann Thorac Surg. 2008; 85:836-44.

8. Gandhi MJ, Pierce RA, Zhang L, Moon MR, Despotis GJ, Moazami N. Use of activated recombinant factor VII for severe coagulopathy post ventricular assist device or orthotopic heart transplant. J Cardiothorac Surg. 2007;2:32-9.

9. Salenger R, Gammie JS, Vander Salm TJ. Postoperative care of cardiac surgical patients. In: Cohn LH, Edmunds LH, eds. Cardiac Surgery in the Adult. 2nd ed. New York: McGraw-Hill; 2003. p. 439-69.

10. Rosenbaum PR, Rubin DB. The central role of the propensity score in observational studies for causal effects. Biometrika. 1983;70:41-55.

11. Austin PC. Propensity-score matching in the cardiovascular surgery literature from 2004 to 2006: a systematic review and suggestions for improvement. J Thorac Cardiovasc Surg. 2007;134:1128-35.

12. Sniecinski RM, Levy JH. Bleeding and management of coagulopathy. J Thorac Cardiovasc Surg. 2011;142:662-7.

13. Sedrakyan A, Wu A, Sedrakyan G, Diener-West M, Tranquilli M, Elefteriades J Aprotinin use in thoracic aortic surgery: safety and outcomes. J Thorac Cardiovasc Surg. 2006;132:909-17.

14. Sundt TM, Kouchoukos NT, Saffitz JE, Murphy SF, Wareing TH, Stahl DJ. Rena dysfunction and intravascular coagulation with aprotinin and hypothermic circulatory arrest. Ann Thorac Surg. 1993;55:1418-24.

15. Raivio P, Suojaranta-Ylinen R, Kuitunen AH. Recombinant factor VIIa in the treatment of postoperative hemorrhage after cardiac surgery. Ann Thorac Surg. 2005;80:66-71.

16. McCall P, Story DA, Karapillai D. Audit of factor VIIa for bleeding resistant to conventional therapy following complex cardiac surgery. Can J Anaesth. 2006; 53:926-33. 
17. von Heymann C, Redlich U, Jain U, Kastrup M, Schroeder T, Sander M, et al. Recombinant activated factor VII for refractory bleeding after cardiac surgery: a retrospective analysis of safety and efficacy. Crit Care Med. 2005;33:2241-6.

18. Hsia CC, Chin-Yee IH, McAlister VC. Use of recombinant activated factor VII in patients without hemophilia: a meta-analysis of randomized control trials. Ann Surg. 2008;248:61-8.

19. Diprose P, Herbertson MJ, O'Shaughnessy D, Gill RS. Activated recombinant factor VII after cardiopulmonary bypass reduces allogeneic transfusion in complex non-coronary cardiac surgery: randomized double-blind placebo-controlled pilot study. Br J Anaesth. 2005;95:596-602.

20. Willis C, Bird R, Mullany D, Cameron P, Phillips L. Use of rFVIIa for critical bleeding in cardiac surgery: dose variation and patient outcomes. Vox Sang. 2009;98:531-7.

21. Gill R, Herbertson M, Vuylsteke A, Olsen PS, von Heymann C, Mythen M, et al. Safety and efficacy of recombinant activated factor VII: a randomized placebo- controlled trial in the setting of bleeding after cardiac surgery. Circulation. 2009; 120:21-7.

22. Martinowitz U, Michaelson M. Guidelines for the use of recombinant activated factor VII (rFVIIa) in uncontrolled bleeding: a report by the Israeli Multidisciplinary rFVIIa Task Force. J Thromb Haemost. 2005;3: 640-8.

23. Ammar T, Silvay G. Factors that influence early extubation: bleeding. J Cardiothorac Vasc Anesth. 1998;12(6 Suppl. 2):28-9.

24. O'Connell KA, Wood JJ, Wise RP, Lozier JN, Braun MM. Thromboembolic adverse events after use of recombinant human coagulation factor VIIa. JAMA. 2006;295:293-8.

25. Masud F, Bostan F, Chi E, Pass SE, Samir H, Stuebing K, et al. Recombinant factor VIIa treatment of severe bleeding in cardiac surgery patients: a retrospective analysis of dosing, efficacy, and safety outcomes. J Cardiothorac Vasc Anesth. 2009;23:28-33. 